\title{
Gingival bleeding and calculus among 12- year-old Chinese adolescents: a multilevel analysis
}

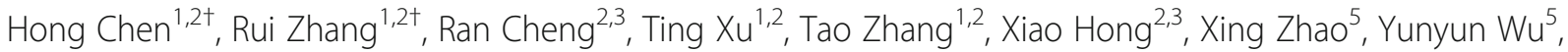
Li Cheng ${ }^{2,3}$ and Tao Hu $u^{2,4^{*}}$

\begin{abstract}
Background: Gingivitis is a common oral health problem, and untreated gingivitis can progress to periodontitis. The objectives of this study were to (1) explore associated factors of gingival bleeding and calculus among 12-yearold adolescents; (2) find predictive models for gingivitis management.

Methods: Four thousand five hundred twenty-five subjects aged 12 in Sichuan Province were investigated. The questionnaire and clinical examination were applied in schools, and two-level logistic regression models were constructed to interpret the effect of individual and contextual factors on Chinese adolescents' gingival bleeding and calculus.

Results: $46.63 \%(95 \% \mathrm{Cl}: 40.71,51.60)$ and $66.94 \%(95 \% \mathrm{Cl}: 56.85,67.45)$ of the subjects presented gingival bleeding and calculus, respectively. For the gingival bleeding cases, the model showed the significant associated indicators were hukou (OR $=0.61,95 \% \mathrm{Cl}: 0.52-0.72)$, family size $(\mathrm{OR}=1.41,95 \% \mathrm{Cl}: 1.19-1.68)$, parental educational level (father: $\mathrm{OR}=0.53,95 \% \mathrm{Cl}: 0.45-0.63$; mother: $\mathrm{OR}=0.71,95 \% \mathrm{Cl}: 0.59-0.86)$, tooth-brushing frequency $(\mathrm{OR}=0.35,95 \%$ $\mathrm{Cl}: 0.26-0.48)$, dental floss use (OR $=0.58,95 \% \mathrm{Cl}: 0.41-0.83)$, sugar-containing drink consumption $(\mathrm{OR}=2.11,95 \% \mathrm{Cl}$ : 1.80-2.49), and dental visit ( $\mathrm{OR}=1.44,95 \% \mathrm{Cl}: 1.19-1.74)$. It also confirmed that gender ( $\mathrm{OR}=1.32,95 \% \mathrm{Cl}: 1.13-$ 1.54), hukou ( $\mathrm{OR}=0.69,95 \% \mathrm{Cl}: 0.59-0.82)$, family size $(\mathrm{OR}=1.34,95 \% \mathrm{Cl}: 1.12-1.59)$, parental educational level (father: $\mathrm{OR}=0.46,95 \% \mathrm{Cl}: 0.39-0.54$; mother: $\mathrm{OR}=0.65,95 \% \mathrm{Cl}: 0.59-0.82)$, tooth-brushing frequency $(\mathrm{OR}=0.57,95 \%$ $\mathrm{Cl}: 0.42-0.78)$, dental floss use $(\mathrm{OR}=0.66,95 \% \mathrm{Cl}: 0.48-0.90)$ and sugar-containing drink consumption $(\mathrm{OR}=1.30$, 95\% Cl: 1.11-1.53) were associated factors for dental calculus.

Conclusions: Gingival bleeding and calculus were common in western Chinese adolescents. Socio-demographic factors including gender, hukou and family factors are strong determinants of gingival health in Chinese adolescents. In addition, health-related lifestyle behaviors such as healthy diet, good hygiene care and more dental visits are good predictors of better gingival status.
\end{abstract}

Keywords: Oral health, Gingival bleeding, Dental calculus, Adolescents, Cross-sectional study

\footnotetext{
* Correspondence: hutao@scu.edu.cn

${ }^{\dagger}$ Hong Chen and Rui Zhang are co-first authors.

${ }^{2}$ State Key Laboratory of Oral Diseases, Sichuan University, Chengdu, PR China

${ }^{4}$ Professor in Department of Preventive Dentistry, West China School of Stomatology, Sichuan University, Chengdu, Sichuan, PR China

Full list of author information is available at the end of the article
}

C C The Author(s). 2020 Open Access This article is licensed under a Creative Commons Attribution 4.0 International License, which permits use, sharing, adaptation, distribution and reproduction in any medium or format, as long as you give appropriate credit to the original author(s) and the source, provide a link to the Creative Commons licence, and indicate if changes were made. The images or other third party material in this article are included in the article's Creative Commons licence, unless indicated otherwise in a credit line to the material. If material is not included in the article's Creative Commons licence and your intended use is not permitted by statutory regulation or exceeds the permitted use, you will need to obtain permission directly from the copyright holder. To view a copy of this licence, visit http://creativecommons.org/licenses/by/4.0/ The Creative Commons Public Domain Dedication waiver (http://creativecommons.org/publicdomain/zero/1.0/) applies to the data made available in this article, unless otherwise stated in a credit line to the data. 


\section{Background}

Oral diseases are the most common noncommunicable diseases, and have become alarming public health problems worldwide [1]. Gingivitis, one of the most common oral health problems, is a mild form of periodontal disease $[1,2]$. Plaque-induced gingivitis is considered to be the most prevalent type of gingivitis [3, 4]. The clinical symptoms of gingivitis include redness, oedema and bleeding at the gingival margin [5]. During puberty (girls, 11-13 years; boys, 13-14 years), periodontal tissues may have an amplified response to local factors: dental plaque, calculus, food debris, and materia alba [6]. And regular removal of these local factors can prevent the occurrence and progression of early gingival disease $[7,8]$.

Dental calculus (mineralized biofilms), located along the gingival margin, is an important gingivitiscontributing factor $[9,10]$. Calculus can't be removed easily from the surface of teeth and provides a substratum for plaque retention in the vicinity to the gingiva [9, 10]. Calculus can also be a surrogate indicator of longterm exposure to biofilm and poor oral hygiene practices [11]. Its presence, along with gingival inflammation, is associated with the initiation and progression of earlyonset periodontitis [10].

Gingivitis and periodontitis can be considered as a continuum of the same inflammatory process, and untreated gingivitis can progress to periodontitis complicated with further tissue destruction and bone reabsorption $[2,3,12]$. Therefore, gingivitis management of adolescents is a prevention strategy for advanced periodontal diseases that might persistently play a crucial role in reducing the periodontal disease burden [2, 4]. The greatest share of oral health problems is attributable to the social conditions in which people live and work, referred to as the social determinants of health $(\mathrm{SDH})$ [13-15]. There are huge disparities in the level of economic development and the availability of healthcare resources in China [16]. The contextual differences are associated with several clinical outcomes of various oral diseases and could thus be related to gingivitis. Other individual SDH factors associated with gingivitis include sex and ethnic inequalities $[13,14]$, family factors $[14$, $17]$, and health behaviors $[14,17,18]$. Therefore, it is important to identify associated individual and contextual factors whose modification can reduce the prevalence of gingival bleeding and calculus in the future, and further, to provide advises on controlling such factors for maintaining a good quality of life [19].

Traditional periodontal examinations are resourceintensive, and a large-scale screening for adolescents is infeasible in China [20]. Recently, self-reported questionnaires have been proposed to predict the probability in periodontal surveys. And the validation of prediction models based on self-reported questionnaires were demonstrated in Taiwan [20], Australia [21], Germany [22], Japan [23], and the United States [24]. Twelve years has been recommended by World Health Organization (WHO) as the indicator age group for international benchmarking of adolescents' oral health [25, 26]. Little is known about the prevalence of gingival bleeding and calculus in adolescents with large sample size in western China. Therefore, the present study aimed to investigate the associated factors for gingival bleeding and dental calculus in 12-year-old adolescents and to build predictive models for gingivitis management and treatment planning.

\section{Methods}

\section{Study design}

This cross-sectional study was a part of the Fourth National Oral Health Survey in China [27-29]. It was a school-based survey conducted from 07/01/2015 to 09/ $17 / 2016$. Ethics approval was obtained from the Stomatological Ethics Committee of the Chinese Stomatological Association and the Ethics Committee of West China Hospital of Stomatology, Sichuan University (Approval No. 2014-003).

\section{Survey sampling}

The target population was selected from about 1, 018, 500 adolescents at the age of 12 years in Sichuan Province. Sichuan Province is located in western China and represents one of the largest provinces with regard to area and population [27, 28]. A complex, multi-stage sampling design [27-29] was used to select participants who were representative of the province's population. In the first stage, six regions (Guang'an District, Chuanshan District, Jinniu District, Da County, Yibin County and Pi County) were obtained from 181 regions with probability-proportional-to-size (PPS) method (Fig. 1). And then a random sampling of schools was selected in

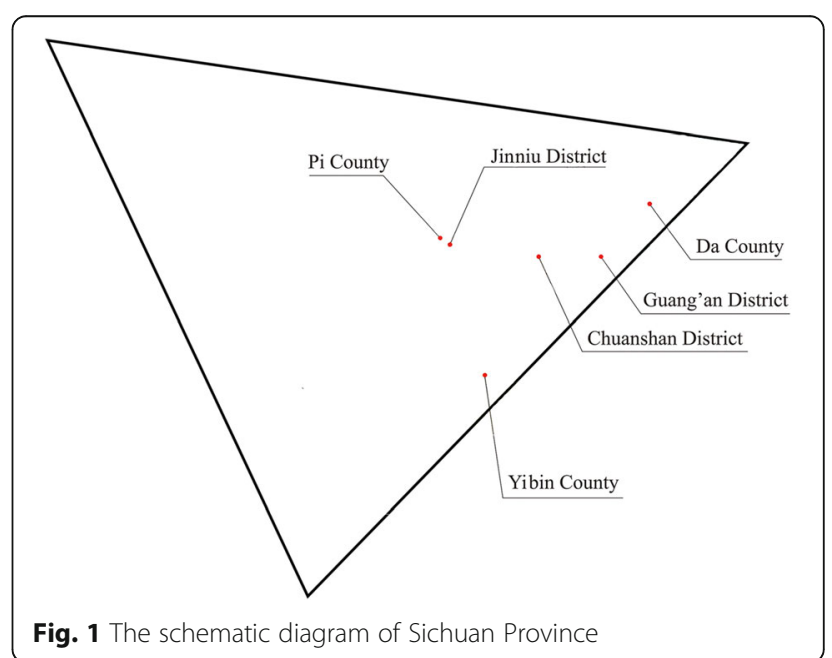


the second stage in each region selected in the first stage $[27,28]$. In the third stage, a computer-generated random number method was used for examinees selection at the aged 12 years [27].

A letter of invitation and informed consent form were sent to the guardian of potential participants firstly, emphasizing that the participation was voluntary. Participants and their statutory guardians were required to sign informed consent forms. Adolescents with serious physical or psychological illness or disadvantages, who were unable or unwilling complete the examination and questionnaire, were excluded. Ultimately, a random sample of 4525 students completed the survey; this number was greater than the expected 4420 participants calculated by the formula:

$$
\mathrm{n}=\operatorname{deff} \frac{\mu^{2}(1-p)}{\varepsilon^{2} p(1-\text { nonresponse })}
$$

in which the design efficiency deff $=2.5[27,28]$, the confidence of investigation $\mu=1.96$, the acceptable error $\varepsilon=$ $15 \%$, the prevalence of caries in people at aged 12 years from the Third National Oral Health Survey in China $p=28.9 \%$ [30] and the non-response rate was 5\%. Of all, gender parity and rural/urban parity would be required $[27,28]$. The gingival bleeding and calculus prevalence rates were 57.7 and $59.0 \%$, respectively [30]. Therefore, respective smaller sample sizes $(N \leq 1318$ and $N \leq 1249)$ would be calculated.

\section{Questionnaire}

The questionnaire was distributed to 4800 participants in 12 years old in Sichuan Province. Every participant was asked to fill an interviewer-administered questionnaire with the guidance of trained dental students in their schools. The independent variables were composed of individual (intermediate SDH) and contextual (regions) factors associated with health (Table 1) [13-15]. These variables were adopted by the World Health Organization Commission on Social Determinants of Health (CSDH). The correlations between gingival status (gingival bleeding and calculus) and Individual factors (gender, ethnicity, hukou, family size, parental educational level, and health-related lifestyle behaviors) [14-17] and contextual factors (regions) were assessed [14]. Health-related lifestyle behaviors were assessed using oral hygiene behaviors (toothbrushing frequency and dental floss usage), diet habits (sugar consumption), dental visit, and dental education $[14,15]$. The independent variables were categorized according to previous studies [14-17]. Contextual variable was the region-level difference. And the 6 regions represented different levels of urbanization [27, 28]. The urbanization that differs

Table 1 Independent variables according to analysis level and SDH categories

\begin{tabular}{|c|c|c|c|}
\hline Level & Classification & Variable & Description and categories \\
\hline \multirow[t]{12}{*}{$\begin{array}{l}\text { 1st Level- } \\
\text { Individual }\end{array}$} & $\begin{array}{l}\text { Intermediate } \\
\text { SDH }\end{array}$ & Gender & Sex of individual, Female/Male \\
\hline & & Ethnicity & Han/Others \\
\hline & & hukou & Rural/Urban \\
\hline & & Family size & Number of Children, One child/More than one child \\
\hline & & Father's educational level & $\begin{array}{l}\text { Schooling of father, Middle school or lower/More than middle } \\
\text { school }\end{array}$ \\
\hline & & Mother's educational level & $\begin{array}{l}\text { Schooling of parents, Middle school or lower/More than middle } \\
\text { school }\end{array}$ \\
\hline & & Toothbrushing frequency & Never/Sometimes/1/ $\geq 2$ \\
\hline & & Dental floss usage & Never/Yes $(\geq 0)$ \\
\hline & & Candy/chocolate /cookies /cakes & $\leq 1 /$ week/>1/week \\
\hline & & $\begin{array}{l}\text { Sugar-containing soft drink/soda/ milk/yogurt } \\
\text { /tea/coffee/water }\end{array}$ & $\leq 1 /$ week/>1/week \\
\hline & & Dentist visit during past year & $>0 / 0$ \\
\hline & & $\begin{array}{l}\text { Frequency of dental education (previous } \\
\text { semester) }\end{array}$ & $>0 / 0$ \\
\hline $\begin{array}{l}\text { 2st Level- } \\
\text { Contextual }\end{array}$ & $\begin{array}{l}\text { Structural } \\
\text { SDH }\end{array}$ & $\begin{array}{l}\text { Regions represent different levels of } \\
\text { urbanization }\end{array}$ & $\begin{array}{l}\text { Guang'an District, Chuanshan District, Jinniu District, Da County, } \\
\text { Yibin County and Pi County }\end{array}$ \\
\hline
\end{tabular}


"between" regions was a value from 0 to 1 . And 6 selected regions were distributed into 3 urbanization levels: high, middle and low levels, two for each level $[27,28]$.

\section{Quality control}

Quality control was conducted as following: three licensed dentists, who had worked for more than 2 years and cooperated with three recorders, were trained by a standard examiner (the fourth examiner) before beginning this survey. No probing of pocket depths was performed, so Cohen's Kappa statistic was used to assess the interexaminer variability of dental caries in adolescents and probing pocket depths in adults. The final Kappa scores obtained on inter- or intra-examiner variability were $\geq 0.8$. Furthermore, the inter-examiner variability in three regions during the survey were $\geq 0.8$ as well.

\section{Clinical assessment}

All clinical procedures were conducted in the adolescents' school in the following sequence. Each participant in the selected regions received an oral health examination by a trained licensed dentist according to the criteria issued by the WHO [25, 31]. The portable equipment used consisted of a dental chair, external light source, plane mouth mirrors, air compressor and the community periodontal index probe (WHO/CPI probe) in conjunction with WHO clinical criteria and visual examinations $[25,32]$. Gingival bleeding was defined as the presence of gingival bleeding upon gentle probing (BOP) in at least one site [25]. The gingival calculus was explored by using CPI probe. The probe started just distal to the midpoint of the buccal surface and then gently moved into the mesial interproximal area. The same procedure was completed on the palatal surface. Bleeding sites were scored after the sites of a single quadrant were probed. Each site was scored as no bleeding $=0$ and bleeding $=1$. A gentle tactile exam was used to locate calculus deposits. Each site was scored as followings: no calculus $=0$; calculus $=1$. Missing (not yet erupted, or extracted) or excludable (dental caries, extensive restorations or orthodontic bands or brackets) were not evaluated [4]. Dental plaque, probing depth, and clinical attachment level were not assessed. No radiographic examination was performed.

After completing the oral examination, all adolescents received an oral evaluation form to take home. This form classified the child's oral health status according to the severity of the oral findings and recommended the timing of their next dental visit $[4,25]$. Those adolescents with calculus would be recommended that they "must visit a dentist as soon as possible".

\section{Statistical analysis}

The data were independently extracted for the statistical analyses by two of the authors (H. C. and R. Z.). The whole information was extracted from the questionnaires and the oral health assessment form. EpiData Version 3.1 (EpiData Association, http:// www.epidata.dk, Epidata Association, Odense, Den- mark) was used for data capture. In order to ensure the consistence and the accuracy of the data, the items were assessed more than 3 times during the input process. Any disagreements or mistakes were assessed further and dealt by the original data in questionnaires.

The simple validation method was used here, and the predictive models were built. Three-quarters of the data were randomly selected and used as training data to develop two-level (first level: individuals; second level: regions) logistic regression models with random intercepts. Firstly, univariate analysis (Pearson's Chisquare test) was used to select factors that might be associated with the outcome variables. After that, predictive models were established with the selected variables mentioned above for gingival bleeding and calculus respectively. The $p$-value, odds ratio (OR) and 95\% confidence intervals $(95 \% \mathrm{CI})$ were estimated to specify the predictive models, and the variables with $p$-value didn't reach 0.05 were removed from the models [33]. The variance partition coefficient (VPC) was calculated to measure the percent of the total variance (summed across the individual level and all contextual levels included in the model) attributable to a given contextual level [34]. Finally, the other one-quarter data (the remaining data) were used for model validation.

All descriptive analyses were performed with the software IBM SPSS Statistics v. 19.0 (IBM Corp., Armonk, NY, USA). The other statistical analyses were implemented by using the lme4 package and Threshold ROC package in $R$ version 2.13.1 ( $R$ Foundation for Statistical Computing, Vienna, Austria).

\section{Results}

A total of 4525 subjects aged 12 years were selected for eligibility in this study with an effective response rate of 94.27\%. Among the participants, $48.60 \%(n=2199)$ of the participants were boys, and $51.40 \%(n=2326)$ were girls. The prevalence of gingival bleeding was $46.63 \%$ $(n=2110 ; 95 \% \mathrm{CI}: 40.71,51.60)$, that of calculus was $66.94 \%$ ( $n=3029$; 95\%CI: 56.85, 67.45). The mean scores of the individual scores of gingival bleeding and calculus were 4.00 and 4.57 , respectively.

The details of the total data were showed in Table 2 . Among, the training dataset characteristics and the results of univariate analyses were presented in Table 3 . As Fig. 2 showed, gingival bleeding in three regions (Guang'an District, Jinniu District, and Pi County) and calculus in two (Yibin County, and Pi County) indicated significant variations (ie, they did not overlap the horizontal line at zero). Therefore, two-level logistic 
Table 2 Descriptive characteristics of the participants $(N=4525)$

\begin{tabular}{|c|c|c|c|c|}
\hline & Number & Percent & $95 \% \mathrm{Cl}$ & \\
\hline Gingival bleeding & 2110 & 46.63 & 45.18 & 48.08 \\
\hline Calculus & 3029 & 66.94 & 65.57 & 68.31 \\
\hline \multicolumn{5}{|l|}{ Areas } \\
\hline Pi County & 590 & 13.04 & 12.06 & 14.02 \\
\hline Chuanshan District & 810 & 17.90 & 16.78 & 19.02 \\
\hline Da County & 838 & 18.52 & 17.39 & 19.65 \\
\hline Yibin County & 845 & 18.67 & 17.54 & 19.81 \\
\hline Jinniu District & 682 & 15.07 & 14.03 & 1.11 \\
\hline Guang'an District & 760 & 16.80 & 15.71 & 17.89 \\
\hline \multicolumn{5}{|l|}{ Gender } \\
\hline Female & 2326 & 51.40 & 49.95 & 52.86 \\
\hline Male & 2199 & 48.60 & 47.14 & 50.05 \\
\hline \multicolumn{5}{|l|}{ hukou } \\
\hline Rural & 2320 & 51.27 & 49.81 & 52.73 \\
\hline Urban & 2205 & 48.73 & 47.27 & 50.19 \\
\hline \multicolumn{5}{|l|}{ Ethnicity } \\
\hline Han & 4475 & 98.90 & 98.59 & 99.20 \\
\hline Others & 50 & 1.10 & 2.80 & 1.41 \\
\hline \multicolumn{5}{|l|}{ Family size } \\
\hline One child & 2883 & 63.71 & 62.31 & 65.11 \\
\hline More than one child & 1642 & 36.29 & 34.89 & 37.69 \\
\hline \multicolumn{5}{|l|}{ Father's educational level } \\
\hline Middle school or lower ${ }^{a}$ & 2960 & 65.41 & 64.03 & 66.80 \\
\hline More than middle school ${ }^{b}$ & 1565 & 34.59 & 33.20 & 35.97 \\
\hline \multicolumn{5}{|l|}{ Mother's educational level } \\
\hline Middle school or lower ${ }^{a}$ & 3314 & 73.24 & 71.95 & 74.53 \\
\hline More than middle school ${ }^{b}$ & 1211 & 26.76 & 25.47 & 28.05 \\
\hline \multicolumn{5}{|l|}{ Toothbrushing frequency } \\
\hline Never & 329 & 7.27 & 6.51 & 8.03 \\
\hline Sometimes & 670 & 14.81 & 13.77 & 15.84 \\
\hline 1 & 1925 & 42.54 & 41.10 & 43.98 \\
\hline$\geq 2$ & 1601 & 35.38 & 33.99 & 36.77 \\
\hline \multicolumn{5}{|l|}{ Dental floss usage } \\
\hline Never & 4273 & 94.43 & 93.76 & 95.10 \\
\hline Yes & 252 & 5.57 & 4.90 & 6.24 \\
\hline \multicolumn{5}{|c|}{ Candy/chocolate /cookies/cakes } \\
\hline$\leq 1 /$ week & 1820 & 40.22 & 38.79 & 41.65 \\
\hline$>1 /$ week & 2705 & 59.78 & 58.35 & 61.21 \\
\hline
\end{tabular}

Sugar-containing soft drink/soda/ milk/yogurt /tea/coffee/water

$\begin{array}{lllll}\leq 1 / \text { week } & 2999 & 66.28 & 64.90 & 67.65 \\ >1 / \text { week } & 1526 & 33.72 & 32.35 & 35.10 \\ \text { Dentist visit during past year } & & & & \\ >0 & 991 & 21.90 & 20.70 & 23.11 \\ 0 & 3534 & 78.10 & 76.89 & 79.30\end{array}$

Table 2 Descriptive characteristics of the participants $(N=4525)$ (Continued)

\begin{tabular}{|c|c|c|c|c|}
\hline & Number & Percent & $95 \% \mathrm{Cl}$ & \\
\hline \multicolumn{5}{|c|}{ Frequency of dental education (previous semester) } \\
\hline$>0$ & 537 & 11.87 & 10.92 & 12.81 \\
\hline 0 & 3988 & 88.13 & 87.19 & 89.08 \\
\hline
\end{tabular}

regression models were built with the selected variables by univariate analyses.

Table 4 presented the eight individual variables significantly associated with gingival bleeding $(p<0.05)$ in two-level logistic regression analysis. The model for gingival bleeding was established including hukou $(\mathrm{OR}=$ $0.61,95 \%$ CI: $0.52-0.72)$, family size (OR $=1.41,95 \% \mathrm{CI}$ : 1.19-1.68), parental educational level (Father: $\mathrm{OR}=0.53$, 95\% CI: $0.45-0.63$; Mother: OR $=0.71,95 \%$ CI: $0.59-$ $0.86)$, tooth-brushing frequency $(\mathrm{OR}=0.35,95 \% \mathrm{CI}$ : $0.26-0.48)$, dental floss use $(\mathrm{OR}=0.58,95 \% \mathrm{CI}: 0.41-$ $0.83)$, sugar-containing drink consumption $(\mathrm{OR}=2.11$, 95\% CI: $1.80-2.49)$, and dental visit $(\mathrm{OR}=1.44,95 \% \mathrm{CI}$ : 1.19-1.74). Regarding the associated factors of calculus, the same model was used and significant variables including gender $(\mathrm{OR}=1.32,95 \% \mathrm{CI}$ : 1.13-1.54), hukou $(\mathrm{OR}=0.69,95 \% \mathrm{CI}: 0.59-0.82)$, family size $(\mathrm{OR}=1.34$, 95\% CI: 1.12-1.59), parental educational level (Father: OR $=0.46,95 \%$ CI: $0.39-0.54 ;$ Mother: $\mathrm{OR}=0.65,95 \%$ CI: $0.59-0.82)$, tooth-brushing frequency $(\mathrm{OR}=0.57$, 95\% CI: 0.42-0.78), dental floss use $(\mathrm{OR}=0.66,95 \% \mathrm{CI}$ : 0.48-0.90) and sugar-containing drink consumption $(\mathrm{OR}=1.30,95 \%$ CI: $1.11-1.53)$ are presented in Table 5. Tables 3 and 4 also displayed the parameters of the fixed and random effects in the two-level logistic regression models and their average intercepts. Finally, the percentage variance explained by the contextual level was 3.13\% for gingival bleeding model and $2.27 \%$ for calculus model.

Based on these models with the average intercepts and coefficients of the variables before, area under the curve (AUC) values were calculated from the receiver operating characteristic (ROC) curves for gingival bleeding and calculus deposits (Table 6). As to the model of gingival bleeding, the estimated AUC values were 0.73 (95\% CI: $0.72,0.75)$ for the training data and 0.75 (95\% CI: 0.73 , 0.78 ) after applying the model by using the validation data. For the model of calculus deposits, the estimated AUC values were 0.68 (95\% CI: $0.66,0.70)$ for the training data and 0.67 (95\% CI: $0.63,0.69$ ) for the validation data. Table 6 showed the performance values for all models, and the optimal cut-off values for the probabilities were calculated using maximized Youden indices. Based on these optimal cut-off values for all samples in the gingival bleeding models, the sensitivity, specificity, 
Table 3 Variables associated with gingival bleeding and calculus using training data as selected by univariate analysis $(n=3394)$

\begin{tabular}{|c|c|c|c|c|c|c|c|c|c|}
\hline \multirow[t]{2}{*}{ Variables } & \multirow[t]{2}{*}{ Categories } & \multicolumn{4}{|c|}{ Gingival bleeding } & \multicolumn{4}{|c|}{ Calculus } \\
\hline & & $\overline{Y e s}$ & No & OR $(95 \% \mathrm{Cl})$ & $p$ & $\overline{\text { Yes }}$ & No & OR $(95 \% \mathrm{Cl})$ & $p$ \\
\hline \multirow[t]{6}{*}{ Region } & Pi County & 264 & 190 & 1 & & 355 & 99 & 1 & \\
\hline & Chuanshan District & 318 & 276 & $0.83(0.65,1.06)$ & 0.14 & 402 & 192 & $0.58(0.44,0.77)$ & $<0.01$ \\
\hline & Da County & 319 & 323 & $0.71(0.56,0.91)$ & 0.01 & 439 & 203 & $0.60(0.46,0.79)$ & $<0.01$ \\
\hline & Yibin County & 315 & 300 & $0.76(0.59,0.96)$ & 0.02 & 381 & 234 & $0.45(0.34,0.60)$ & $<0.01$ \\
\hline & Jinniu District & 137 & 376 & $0.26(0.20,0.34)$ & $<0.01$ & 310 & 203 & $0.43(0.32,0.56)$ & $<0.01$ \\
\hline & Guang'an District & 213 & 363 & $0.42(0.33,0.54)$ & $<0.01$ & 373 & 203 & $0.51(0.39,0.68)$ & $<0.01$ \\
\hline \multirow[t]{2}{*}{ Gender } & Female & 805 & 949 & 1 & & 1112 & 642 & 1 & \\
\hline & Male & 761 & 879 & $1.02(0.89,1.17)$ & 0.77 & 1148 & 492 & $1.35(1.17,1.56)$ & $<0.01$ \\
\hline \multirow[t]{2}{*}{ Ethnicity } & Others & 20 & 19 & 1 & & 31 & 8 & 1 & \\
\hline & Han & 1546 & 1809 & $0.81(0.43,1.53)$ & 0.52 & 2229 & 1126 & $0.51(0.22,1.06)$ & 0.09 \\
\hline \multirow[t]{2}{*}{ hukou } & Rural & 938 & 809 & 1 & & 1248 & 499 & 1 & \\
\hline & Urban & 628 & 1019 & $0.53(0.46,0.61)$ & $<0.01$ & 1012 & 635 & $0.64(0.55,0.74)$ & $<0.01$ \\
\hline \multirow[t]{2}{*}{ Family size } & One child & 982 & 1178 & 1 & & 1420 & 740 & 1 & \\
\hline & More than one child & 584 & 650 & $1.08(0.94,1.24)$ & 0.30 & 840 & 394 & $1.11(0.96,1.29)$ & 0.17 \\
\hline \multirow[t]{2}{*}{ Father's educational level } & Middle school or lower ${ }^{a}$ & 1168 & 1045 & 1 & & 1624 & 589 & 1 & \\
\hline & More than middle school ${ }^{b}$ & 398 & 783 & $0.45(0.39,0.53)$ & $<0.01$ & 636 & 545 & $0.42(0.36,0.49)$ & $<0.01$ \\
\hline \multirow[t]{2}{*}{ Mother's educational level } & Middle school or lower ${ }^{a}$ & 1250 & 1240 & 1 & & 1756 & 734 & 1 & \\
\hline & More than middle school ${ }^{b}$ & 316 & 588 & $0.53(0.46,0.62)$ & $<0.01$ & 504 & 400 & $0.53(0.45,0.62)$ & $<0.01$ \\
\hline \multirow[t]{4}{*}{ Brushing frequency (times/day) } & Never & 148 & 111 & 1 & & 188 & 71 & 1 & \\
\hline & Sometimes & 348 & 142 & $1.84(1.34,2.52)$ & $<0.01$ & 399 & 91 & $1.66(1.16,2.36)$ & 0.01 \\
\hline & 1 & 739 & 711 & $0.78(0.60,1.02)$ & 0.07 & 1013 & 437 & $0.88(0.65,1.17)$ & 0.38 \\
\hline & $\geq 2$ & 331 & 864 & $0.29(0.22,0.38)$ & $<0.01$ & 660 & 535 & $0.47(0.34,0.62)$ & $<0.01$ \\
\hline \multirow[t]{2}{*}{ Dental floss use } & Never & 1512 & 1698 & 1 & & 2161 & 1049 & 1 & \\
\hline & Yes & 54 & 129 & $0.47(0.33,0.64)$ & $<0.01$ & 99 & 85 & $0.56(0.42,0.76)$ & $<0.01$ \\
\hline \multirow[t]{2}{*}{ Candy/chocolate /cookies /cakes } & $\leq 1 /$ week & 594 & 786 & 1 & & 907 & 473 & 1 & \\
\hline & $>1 /$ week & 972 & 1042 & $1.23(1.08,1.42)$ & $<0.01$ & 1353 & 661 & $1.07(0.92,1.23)$ & 0.38 \\
\hline \multirow{2}{*}{$\begin{array}{l}\text { Sugar-containing soft drink/soda/ } \\
\text { milk/yogurt /tea/coffee/water }\end{array}$} & $\leq 1 /$ week & 377 & 764 & 1 & & 701 & 440 & 1 & \\
\hline & $>1 /$ week & 1189 & 1064 & 2.26 (1.95 2.63) & $<0.01$ & 1559 & 694 & $1.41(1.21,1.64)$ & $<0.01$ \\
\hline \multirow{2}{*}{$\begin{array}{l}\text { History of dental visit } \\
\text { (previous year) }\end{array}$} & No & 1224 & 1436 & 1 & & 1779 & 881 & 1 & \\
\hline & Yes & 342 & 392 & $1.02(0.87,1.21)$ & 0.78 & 481 & 253 & $0.94(0.79,1.12)$ & 0.49 \\
\hline \multirow{2}{*}{$\begin{array}{l}\text { Frequency of dental curricula } \\
\text { (previous semester) }\end{array}$} & 0 & 1424 & 1569 & 1 & & 2020 & 973 & 1 & \\
\hline & $\geq 1$ & 142 & 259 & $0.60(0.49,0.75)$ & $<0.01$ & 240 & 161 & $0.72(0.58,0.89)$ & $<0.01$ \\
\hline
\end{tabular}

Abbreviations: ${ }^{a}$ Middle school or lower: $\leq 9$ years; ${ }^{b}$ More than middle school: $>9$ years

positive predictive value (PPV), negative predictive value (NPV), Youden index and predicted prevalence were determined.

\section{Discussion}

This was a cross-sectional study included a relatively large sample size $(N=4525)$ to assess the prevalence of gingival bleeding and dental calculus in western Chinese adolescents. The study found high prevalence of both gingival bleeding and calculus, $46.63 \%$ of participants showed gingival bleeding, and $66.94 \%$ had calculus deposits. Here multistage sampling was used in this study, which was considered as a more accurate sampling [35, 36]. It is also a convenient and effective way for finding the survey sample and is particularly suitable for our study, which needed a large sample size $[35,36]$. A higher prevalence of calculus was calculated than that of gingival bleeding. These results are contrast with the findings of previous studies [4,37]. The reason may be the different qualities of water in western China, with 

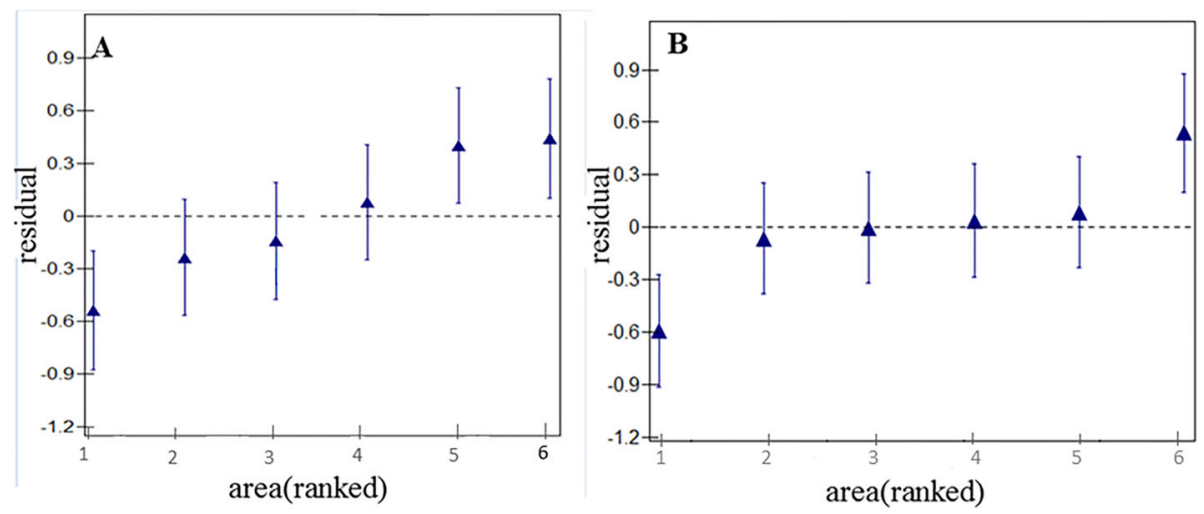

Fig. 2 Plots of regions residuals with 95\%Cls. (a) gingival bleeding and (b) calculus. a: sequencing from left to right: Jinniu District, Guang'an District, Yibin County, Da County, Chuanshan District and Pi County. b: sequencing from left to right: Yibin County, Da County, Guang'an District, Jinniu District, Chuanshan District and Pi County

high hardness and much salinity [38, 39]. Therefore, the effect of water supply on the oral health is needed to explore in the further study.

In the present study, multi-level models were used to correctly specify the data structure and to demonstrate the significant variables of gingival bleeding and calculus. As screening approach for assessing the associated factors of gingival bleeding and calculus, adolescents could be encouraged to modify bad behaviors to decrease the prevalence. For simple validation method, we randomly divided our study population into three-quarters and one-quarter samples used in the previous studies [20, 40]. Simple random sample was used to select the training data and validation data. Actually, the dataset selection should be considered its multilevel structure [41]. If this is not done, the analysis may give incorrect or potentially misleading results. Because the hierarchical datasets may be close to flat and candidate models can be swamped by random fluctuations [41]. Therefore, we confirmed the distribution of the samples in 6 regions were similar, and no significant bias existed. Table 6 showed the summary findings of our models [20]. Among, Youden's index provides a measure of validity by considering both sensitivity and specificity [42]. Here the low values of Youden indices suggested the low predictive capacity of the models. The results also implied the models could only be used as a first-line screening tool. Regular dental visit is still needed. Previous study said ethnical and methodological differences would influence the predictive capacity [42]. In addition, this epidemiological survey included only 6 regions. A small region size cannot produce valid and accurate estimates for multi-level logistic regression models [43]. Further we will increase the regions and adolescents included. And factors in questionnaire, especially contextual variables, should be added in the survey as well. Then the prediction models would obtain more accuracy.
From a conceptual perspective, the results contribute to our understanding of the determinants of gingival bleeding and calculus. The popularity of calculus was higher in male gender, however, there was little sex inequalities presented in the outcome of gingival bleeding. Previous studies confirmed that prevalence of gingivitis in puberty was correlated with elevation in systemic levels of the sex hormones (testosterone in boys and estradiol and progesterone in girls) [4, 6, 7]. Increased serum levels (testosterone in boys, and estradiol, progesterone in girls) are positively associated with high levels of Prevotella (P.) intermedia and P. nigrescens [6]. The age peak of gingivitis in girls (11-13 years) was earlier than that in boys (13-14 years) $[4,6,7]$. Therefore, the increased sex hormones in girls may interfere the results. Along with gender, age and income, hukou is quite a common variable on individual behavior in social and economic studies in China $[44,45]$. It was proved to be associated with dental health. But previous studies were focused on its impact on dental caries [46, 47]. In this study, the periodontal status was better in urban hukou than that in rural hukou. The reason might be people with rural hukou didn't have full access to oral-related public health services funded by the tax revenue [46, 47].

Several characteristics, broadly categorized as childlevel, family-level and community-level, could influence the periodontal diseases in adolescents $[48,49]$. Familylevel characteristics affect both the child-level factors, such as self-care practices and service utilization, and periodontal disease status $[50,51]$. This is because parents and adolescents share similar cariogenic and periodontal pathogenic microbiota $[52,53]$. The results of our analyses suggested that sociodemographic characteristics of adolescents' family at 12 years of age, as well as family environment, were important determinants of the occurrence of gingival bleeding and calculus in adolescents. In this study, the only child had lower prevalence 
Table 4 Selected variables using training data shown to be associated with gingival bleeding by multi-level logistic regression analyses $(n=3394)$

\begin{tabular}{|c|c|c|c|c|}
\hline \multirow[t]{2}{*}{ Variables } & \multirow[t]{2}{*}{ Categories } & \multirow{2}{*}{$\begin{array}{l}\text { Null } \\
\text { model }\end{array}$} & \multicolumn{2}{|c|}{ Model with individual and contextual variables } \\
\hline & & & OR $(95 \% \mathrm{Cl})$ & $p$ \\
\hline \multicolumn{5}{|l|}{ Fixed effect } \\
\hline \multicolumn{5}{|l|}{ Individual level } \\
\hline \multirow[t]{2}{*}{ hukou } & & & 1 & \\
\hline & Rural & & $0.61(0.52,0.72)$ & $<0.01$ \\
\hline \multirow[t]{2}{*}{ Family size } & Urban & & 1 & \\
\hline & One child & & $1.41(1.19,1.68)$ & $<0.01$ \\
\hline \multirow[t]{2}{*}{ Father's educational level } & More than one child & & 1 & \\
\hline & Middle school or lower ${ }^{\text {a }}$ & & $0.53(0.45,0.63)$ & $<0.01$ \\
\hline \multirow[t]{2}{*}{ Mother's educational level } & More than middle school ${ }^{b}$ & & 1 & \\
\hline & & & $0.71(0.59,0.86)$ & $<0.01$ \\
\hline \multirow[t]{4}{*}{ Brushing frequency (times/day) } & & & 1 & \\
\hline & & & $2.03(1.46,2.82)$ & $<0.01$ \\
\hline & & & $0.93(0.70,1.23)$ & 0.60 \\
\hline & & & $0.35(0.26,0.48)$ & $<0.01$ \\
\hline \multirow[t]{2}{*}{ Dental floss use } & & & 1 & \\
\hline & & & $0.58(0.41,0.83)$ & $<0.01$ \\
\hline \multirow{2}{*}{$\begin{array}{l}\text { Sugar-containing soft drink/Pop/ } \\
\text { milk/yogurt/tea/coffee/water }\end{array}$} & & & 1 & \\
\hline & & & $2.11(1.80,2.49)$ & $<0.01$ \\
\hline \multirow[t]{2}{*}{ Dental visit (previous year) } & & & 1 & \\
\hline & & & $1.44(1.19,1.74)$ & $<0.01$ \\
\hline \multicolumn{5}{|l|}{ Random effect } \\
\hline Contextual level variance $\left(\mathrm{SE}^{\mathrm{C}}\right)$ & & $0.20(0.12)$ & $0.13(0.08)$ & 0.10 \\
\hline $\mathrm{AIC}^{\mathrm{d}}$ & & 4562.8 & 4051.4 & \\
\hline Average intercept & & -0.173 & -0.02246 & \\
\hline VPC & & 0.0469 & 0.031252 & \\
\hline
\end{tabular}

Abbreviations: ${ }^{\mathrm{a}}$ Middle school or lower, $\leq 9$ years; ${ }^{\mathrm{b}}$ More than middle school, $>9$ years; ${ }^{\mathrm{C}} S E$ standard error, ${ }^{\mathrm{d}}$ AIC Akaike Information Criteria, ${ }^{\mathrm{e}} V P C$ variance partitioning coefficient attributable to the second level (regions)

of gingival bleeding and calculus than child with siblings. The results were similar with many previous studies that proved less adolescent number in one family was easier to have better periodontal condition $[54,55]$. In addition, our study observed a positive impact of higher level of parental education on the gingival status of adolescents, and mothers' and fathers' education levels, respectively, could be used as a predictor of gingival bleeding and calculus.

As to the self-care practices and habits, unhealthy diet behaviors (high carbohydrate diet) and bad hygiene care (less brushing frequency per day) increased the prevalence of gingival bleeding and calculus. However, no significant difference was found between adolescents brushing once/day and those did not brush at all. This thought-provoking point surprised us. The potential reasons to interpret this phenomenon are as following: first, gingivitis is caused by multiple factors [54], including not only brushing frequency, but also duration of brushing, brushing method, and the type of dentifrice [55]. Second, people with irregular health habits, such as meals, tooth-brushing and bedtime, are more prone to disease $[56,57]$. Third, reporting bias and undercounting of errors were unavoidable in this survey.

The periodontal status of the included adolescents in this survey was unsatisfactory, and most of them had calculus. However, a somewhat high number of adolescents claimed to brush their teeth at least once a day. This inconsistency between periodontal health and reported dental hygiene practice may be a result of the adolescents having not acquired the proper brushing techniques. Motivation to implement the instructions given for oral health care and regular enforcement are essential in promoting adolescents' oral health [58]. In China, dental curricula are not enforced and only provided in certain schools in the health education textbook 
Table 5 Selected variables using training data shown to be associated with dental calculus, evaluated by multi-level logistic regression analyses $(n=3394)$

\begin{tabular}{|c|c|c|c|c|}
\hline \multirow[t]{2}{*}{ Variables } & \multirow[t]{2}{*}{ Categories } & \multirow[t]{2}{*}{ Null model } & \multicolumn{2}{|c|}{ Model with individual and contextual variables } \\
\hline & & & $\mathrm{OR}(95 \% \mathrm{Cl})$ & $p$ \\
\hline \multicolumn{5}{|l|}{ Fixed effect } \\
\hline \multicolumn{5}{|l|}{ Individual level } \\
\hline \multirow[t]{2}{*}{ Gender } & Female & & 1 & \\
\hline & Male & & $1.32(1.13,1.54)$ & $<0.01$ \\
\hline \multirow[t]{2}{*}{ hukou } & Rural & & 1 & \\
\hline & Urban & & $0.69(0.590 .82)$ & $<0.01$ \\
\hline \multirow[t]{2}{*}{ Family size } & One child & & 1 & \\
\hline & More than one child & & $1.34(1.12,1.59)$ & $<0.01$ \\
\hline \multirow[t]{2}{*}{ Father's educational level } & Middle school or lower ${ }^{a}$ & & 1 & \\
\hline & More than middle school ${ }^{b}$ & & $0.46(0.390 .54)$ & $<0.01$ \\
\hline \multirow[t]{2}{*}{ Mother's educational level } & Middle school or lower ${ }^{a}$ & & 1 & \\
\hline & More than middle school ${ }^{b}$ & & $0.65(0.590 .82)$ & $<0.01$ \\
\hline \multirow[t]{4}{*}{ Brushing frequency (times/day) } & Never & & 1 & \\
\hline & Sometimes & & $1.76(1.21,2.54)$ & $<0.01$ \\
\hline & One & & $1.04(0.771 .42)$ & 0.79 \\
\hline & $\geq$ Twice & & $0.57(0.420 .78)$ & $<0.01$ \\
\hline \multirow[t]{2}{*}{ Dental floss use } & Never & & 1 & \\
\hline & Yes & & $0.66(0.480 .90)$ & 0.01 \\
\hline \multirow{2}{*}{$\begin{array}{l}\text { Sugar-containing soft drink/Pop/ } \\
\text { milk/yogurt/tea/coffee/water }\end{array}$} & $\leq 1 /$ week & & 1 & \\
\hline & $>1 /$ week & & $1.30\left(\begin{array}{ll}1.11 & 1.53\end{array}\right)$ & $<0.01$ \\
\hline \multirow[t]{2}{*}{ Dental visit (last year) } & No & & 1 & \\
\hline & Yes & & $1.15(0.96$ 1.39) & 0.14 \\
\hline \multirow{2}{*}{$\begin{array}{l}\text { Frequency of dental curricula } \\
\text { (last semester) }\end{array}$} & 0 & & 1 & \\
\hline & $\geq 1$ & & $0.85(0.67,1.07)$ & 0.16 \\
\hline \multicolumn{5}{|l|}{ Random effect } \\
\hline Contextual level variance $\left(\mathrm{SE}^{\mathrm{c}}\right)$ & & $0.065(0.42)$ & $0.12(0.07)$ & 0.11 \\
\hline$A I C^{d}$ & & 4277.8 & 3985.3 & \\
\hline Average intercept & & 0.715 & 1.06365 & \\
\hline $\mathrm{VPC}^{\mathrm{e}}$ & & 0.01438 & 0.022693 & \\
\hline
\end{tabular}

Abbreviations: ${ }^{\mathrm{a}}$ Middle school or lower: $\leq 9$ years; ${ }^{\mathrm{b}}$ More than middle school: $>9$ years; ${ }^{\mathrm{c}} S E$ standard error, ${ }^{\mathrm{d}} A / C$ Akaike Information Criteria, ${ }^{\mathrm{e}} V P C$ variance partitioning coefficient

[59]. Here, the popularity of dental curricula and the relationship between this intervention and oral health were explored. Dental curricula showed limited impact on the oral health improvement, which suggested that better and more effective oral health education was essential.

Only $20 \%$ of the students had visited a dentist during the last 12 months, which was a lower proportion than that found in the other surveys [60]. However, a higher gingivitis rate was found in the adolescents who had visited dentists. The trend was consisted with previous studies $[35,36]$. This might be due to the common problem-oriented dental-care-seeking behavior in China. It was plausible that adolescents were brought to visit dentists for pain and infection $[35,36]$. The limited availability of dental-care resources might be another reason. The dentist to population ratio is around 1:30,000 in China and the number of dentists is even fewer in rural regions [61].

Some limitations need to be analyzed in this investigation. This was a cross-validation analysis, an external validation was not possible because of the limited numbers of variables obtained from other screening database. In addition, the questionnaires were completed by the participants; thus, certain limitations were unavoidable, such as response bias, reporting bias and undercounting of errors. Moreover, more contextual variables that 
Table 6 Summary findings of models in gingival bleeding and calculus

\begin{tabular}{llll}
\hline Performance Measures & Predictive model with total samples (\%) & Predictive model with training data (\%) & Predictive model with validation data (\%) \\
\hline $\begin{array}{ll}\text { Gingival bleeding } \\
\text { Sensitivity }\end{array}$ & $69.05(67.08,71.02)$ & $68.77(66.48,71.07)$ & $69.85(66.00,73.71)$ \\
Specificity & $66.75(64.87,68.63)$ & $66.19(64.02,68.36)$ & $68.48(64.73,72.24)$ \\
PPV & $64.47(62.50,66.44)$ & $63.54(61.25,65.83)$ & $67.26(63.39,71.13)$ \\
NPV $^{b}$ & $71.17(69.30,73.04)$ & $71.22(69.07,73.37)$ & $71.02(67.29,74.76)$ \\
Accuracy & $67.82(66.46,69.18)$ & $67.38(65.81,68.96)$ & $69.14(66.45,71.83)$ \\
AUC & $73.81(72.38,75.25)$ & $73.29(71.63,74.96)$ & $75.34(72.53,78.15)$ \\
Predicted prevalence & $49.94(48.49,51.40)$ & $53.86(52.18,55.34)$ & $49.96(47.04,52.87)$ \\
Youden index & $35.93(33.20,38.65)$ & $34.97(31.81,38.12)$ & $38.34(32.95,43.72)$ \\
Dental calculus & & & $65.02(61.65,68.39)$ \\
Sensitivity & $67.12(996,68.79)$ & $67.83(65.91,69.78)$ & $57.73(52.65,62.82)$ \\
Specificity & $59.43(56.94,61.91)$ & $59.96(57.11,62.82)$ & $76.57(73.32,79.82)$ \\
PPV & $77.01(75.40,78.61)$ & $77.15(75.31,79.00)$ & $43.72(39.28,48.17)$ \\
NPV & $47.16(44.91,49.42)$ & $48.33(45.76,50.90)$ & $62.69(59.87,65.51)$ \\
Accuracy & $64.57(63.18,65.97)$ & $65.20(63.60,66.81)$ & $66.55(63.29,69.28)$ \\
AUC & $67.83(66.19,69.46)$ & $68.27(66.39,70.16)$ & $57.73(54.86,60.62)$ \\
Predicted prevalence & $58.34(56.9159 .78)$ & $58.54(56.89,60.20)$ & $22.75(16.65,28.86)$ \\
Youden index & $26.54(23.54,29.54)$ & $27.80(24.36,31.24)$ &
\end{tabular}

Abbreviations: ${ }^{\mathrm{a}} \mathrm{PPV}$ positive predictive value, ${ }^{\mathrm{b}} \mathrm{NPV}$ negative predictive value, ${ }^{\mathrm{c}} A U \mathrm{C}$ area under the receiver operating characteristic (ROC) curve

reflect the inequitable distribution of dental-care resources and oral health coverage, water supply and utilization of dental services need to be assessed. At last, this epidemiological survey included only 6 regions in Sichuan Province based on a complex sample design. A small region size may hardly represent the whole province's population, and generate biased estimates. Because of these limitations, our results should be interpreted with caution.

The findings from this study can serve as a warning sign for adolescents and policy makers in western China. Oral health education and practice should be strengthened, especially for adolescents with high risk. Individual, parents and educators should be instructed about the prevention and management of gingival disease. And oral health educational programs for parents are also imperative. Tackling the inequitable distribution of dental care resources is very important. Due to lack of dentists in some regions, the cultivation of a community-based dentist may be a priority, which can improve the adolescents' access to dental care.

\section{Conclusion}

Gingival bleeding and calculus were prevalent among 12year-old western Chinese adolescents. Unhealthy diet behaviors and insufficient hygiene care were related to the high prevalence. Individual, family, and school should be instructed about the prevention and management for improving the gingival status of adolescents. Moreover, regular dental visit is also recommended.

\section{Abbreviations}

SDH: Social determinants of health; CSDH: Commission on social determinants of health; WHO: World Health Organization; PPS: Probabilityproportional-to-size; BOP: Bleeding on probing; VPC: Variance partition coefficient; ROC: Receiver operating characteristic; AUC: Area under the ROC curve; AIC: Akaike information criterion; CPI probe: Community periodontal index probe; SE: Standard error; PPV: Positive predictive value; NPV: Negative predictive value

\section{Acknowledgements}

The authors thank the technical assistance provided by the Sichuan Centre for Disease Control and Prevention, survey team from the West China Hospital of Stomatology, Sichuan University, P. R. China.

\section{Authors' contributions}

CH ZR CL HT: Principal investigator involved in study conception and design, acquisition of data, analysis and interpretation of data; drafted the manuscript and provided final approval of the version to be published. CR: Interpreted the data, revised and approved the manuscript. XT: Interpretation of data, revised and approved the manuscript. ZT: Data collection and approved the manuscript. HX: Drafting the article or revising it critically for important intellectual content. CH ZR ZX WYY: Made substantial contributions to the design, performed the statistical analysis and interpretation of data, revised and approved the manuscript. All authors read and approved the final manuscript.

\section{Funding}

This survey was funded by National Natural Science Foundation of China grant (No. 81970948), and Scientific Research in the Public Interest grant (No. 201502002). The funders of the study had no role in the design of the study and collection, analysis, and interpretation of data and in writing the manuscript. 


\section{Availability of data and materials}

The datasets used and analyzed during the current study are available from the corresponding author on reasonable request.

\section{Ethics approval and consent to participate}

Ethical approvals were obtained from the Stomatological Ethics Committee of the Chinese Stomatological Association and the Ethics Committee of West China Hospital of Stomatology, Sichuan University (Approval No. 2014-003). All adolescents and their statutory guardians were required to sign an informed consent form, the informed consent form contains the survey content about adolescents and their statutory guardians.

\section{Consent for publication}

Not applicable.

\section{Competing interests}

The authors declare that they have no competing interests.

\section{Author details}

${ }^{1}$ Graduate Student in Department of Preventive Dentistry, West China School \& Hospital of Stomatology, Sichuan University, Chengdu, China. ${ }^{2}$ State Key Laboratory of Oral Diseases, Sichuan University, Chengdu, PR China. ${ }^{3}$ Associate Professor in Department of Preventive Dentistry, West China School of Stomatology, Sichuan University, Chengdu, China. ${ }^{4}$ Professor in Department of Preventive Dentistry, West China School of Stomatology, Sichuan University, Chengdu, Sichuan, PR China. ${ }^{5}$ West China School of Public Health, Sichuan University, Chengdu, China.

\section{Received: 15 December 2019 Accepted: 28 April 2020} Published online: 19 May 2020

\section{References}

1. Peres MA, Macpherson LMD, Weyant RJ, Venturelli R, Mathur MR, et al. Oral diseases: a global public health challenge. Lancet. 2019;394(10194):249-60.

2. Kinane DF, Stathopoulou PG, Papapanou PN. Periodontal diseases. Nat Rev Dis Primers. 2017;3(1):1-14

3. Leishman SJ, Seymour GJ, Ford PJ. Local and systemic inflammatory responses to experimentally induced gingivitis. Dis Markers. 2013;35(5):543-9.

4. Elias-Boneta AR, Ramirez K, Rivas-Tumanyan S, Murillo M, Toro MJ. Prevalence of gingivitis and calculus in 12-year-old Puerto Ricans: a crosssectional study. BMC Oral Health. 2018;18(1):13.

5. Biesbrock A, He T, DiGennaro J, Zou Y, Ramsey D, Garcia-Godoy F. The effects of bioavailable gluconate chelated stannous fluoride dentifrice on gingival bleeding: meta-analysis of eighteen randomized controlled trials. J Clin Periodontol. 2019;46(12):1205-16.

6. Chaitra TR, Manuja N, Sinha AA, Kulkarni AU. Hormonal effect on gingiva: pubertal gingivitis. BMJ Case Rep. 2012. https://doi.org/10.1136/bcr.2012. 006193.

7. Nakagawa S, Fujii H, Machida Y, Okuda K. A longitudinal study from prepuberty to puberty of gingivitis: correlation between the occurrence of Prevotella intermedia and sex hormones. J Clin Periodontol. 1994;21(10): 658-65.

8. Das UM, Vadakkekuttical RJ, Kanakkath H, Shankunni SP. Dental health awareness, attitude, and dental health-care seeking practices as risk indicators for the prevalence of periodontal disease among 15-17-year-old school children in Kozhikode district, Kerala, India. J Indian Soc Periodontol. 2017:21:144-51.

9. White DJ. Dental calculus: recent insights into occurrence, formation, prevention, removal and oral health effects of supragingival and subgingival deposits. Eur J Oral Sci. 1997;105:508-22.

10. Jepsen S, Deschner J, Braun A, Schwarz F, J E. Calculus removal and the prevention of its formation. Periodontol 2000. 2011;55(1):167-88.

11. Davies RM, Ellwood RP, Volpe AR, Petrone ME. Supragingival calculus and periodontal disease. Periodontol 2000. 1997;15(1):74-83.

12. Scapoli L, Girardi A, Palmieri A, Martinelli M, Cura F, Lauritano D, et al. Quantitative analysis of periodontal pathogens in periodontitis and gingivitis. J Biol Regul Homeost Agents. 2015;29(3):101-10.

13. Bomfim RA, Herrera DR, De-Carli AD. Oral health-related quality of life and risk factors associated with traumatic dental injuries in Brazilian children: a multilevel approach. Dent Traumatol. 2017;33(5):358-68.
14. Viner RM, Ozer EM, Denny S, Marmot M, Resnick M, Fatusi A, et al. Adolescence and the social determinants of health. Lancet. 2012;379(9826): 1641-52.

15. Celeste RK, Nadanovsky P. Ponce de Leon a, Fritzell J. the individual and contextual pathways between oral health and income inequality in Brazilian adolescents and adults. Soc Sci Med. 2009;69(10):1468-75.

16. Yang X-y, N-m Z, Diao X, Mao X, Y-p L. Epidemiological analysis of pulmonary tuberculosis in Sichuan Province, China, 2000-2006. Int J Infect Dis. 2008;12(5):534-41.

17. Jaghasi I, Hatahet W, Dashash M. Dietary patterns and oral health in schoolchildren from Damascus, Syrian Arab Republic. East Mediterr Health J. 2012;18:358-64.

18. Taani DQ. Periodontal awareness and knowledge, and pattern of dental attendance among adults in Jordan. Int Dent J. 2002;52(2):94-8.

19. Kandelman D, Arpin S, Baez RJ, Baehni PC, Petersen PE. Oral health care systems in developing and developed countries. Periodontol 2000. 2012; 60(1):98-109.

20. Lai H, Su CW, Yen AM, Chiu SY, Fann JC, Wu WY, et al. A prediction model for periodontal disease: Modelling and validation from a National Survey of 4061 Taiwanese adults. J Clin Periodontol. 2015;42(5):413-21.

21. Slade GD. Interim analysis of validity of periodontitis screening question in the Austra lian population. J Clin Periodontol. 2007;78:1463-70.

22. Zhan Y, Holtfreter B, Meisel P, Hoffmann T, Micheelis W, Dietrich T, et al. Prediction of periodontal disease: model ling and validation in different general German populations. J Clin Periodontol. 2014;41(3):224-31.

23. Yamamoto T, Koyama R, Tamaki N, Maruyama T, Tomofuji T, Ekuni D, et al. Validity of a questionnaire for periodontitis screening of Japanese employees. J Occup Health. 2009;51(2):137-43.

24. Gilbert GH, Litaker MS. Validity of self-reported periodontal status in the Florida dental care study. J Periodontol. 2007;78(7):1429-38.

25. World Health Organization (WHO). Oral health surveys: basic methods. 5th ed. Geneva: World Health Organization; 2013.

26. Pontigo-Loyola AP, Medina-Solis CE, Borges-Yañez SA, Patiño-Marín N, IslasMárquez A, Maupome G. Prevalence and severity of dental caries in adolescents aged 12 and 15 living in communities with various fluoride concentrations. J Public Health Dent. 2007;67(1):8-13.

27. Yin W, Yang YM, Chen H, Li X, Wang Z, Cheng L, et al. Oral health status in Sichuan Province: findings from the oral health survey of Sichuan, 20152016. Int J Oral Sci. 2017;9(1):10-5.

28. Wang L, Cheng L, Yuan B, Hong X, Hu T. Association between socioeconomic status and dental caries in elderly people in Sichuan Province, China: a cross-sectional study. BMJ Open. 2017;7(9):e016557.

29. Qin Y, Zhang R, Yuan B, Xu T, Chen H, Yang Y, et al. Structural equation modelling for associated factors with dental caries among 3-5-year-old children: a cross-sectional study. BMC Oral Health. 2019;19(1):102.

30. Cao CF. Prevalences of periodontal diseases and dental caries in China: reanalysis of the data from the third National Epidemiological Survey on Oral health. Zhonghua Kou Qiang Yi Xue Za Zhi. 2013;48:257-9.

31. da Fonseca RCL, Antunes JLF, Cascaes AM, Bomfim RA. Analysis of the combined risk of oral problems in the oral health-related quality of life of Brazilian adolescents: multilevel approach. Clin Oral Investig. 2020;24(2):857-66.

32. Hong-Ying W, Petersen PE, Jin-You B, Bo-Xue Z. The second national survey of oral health status of children and adults in China. Int Dent J. 2002;52(4): 283-90.

33. LeBlanc AG, Broyles ST, Chaput J-P, Leduc G, Boyer C, Borghese MM, et al. Correlates of objectively measured sedentary time and self-reported screen time in Canadian children. Int J Behav Nutr Phys Act. 2015;12(1):38.

34. Herkrath FJ, Vettore MV, Werneck GL. Contextual and individual factors associated with dental services utilisation by Brazilian adults: a multilevel analysis. PLoS One. 2018;13(2):e0192771.

35. Zhang S, Xu B, Liu J, Lo EC, Chu C-H. Dental and periodontal status of 12year-old Dai school children in Yunnan Province, China: a cross-sectional study. BMC Oral Health. 2015;15(1):117.

36. Zhang S, Liu J, Lo EC, Chu C-H. Dental and periodontal status of 12-year-old Bulang children in China. BMC Oral Health. 2014;14(1):32.

37. Du A, Zhang H, Chen C, Zhang F, Liu X, Zhang Z, et al. Oral health of 12year-old children in Jilin province, China: a population-based epidemiological survey. Medicine (Baltimore). 2019;98(51):e18463.

38. Wang Y, Tang K, Xu Z, Tang Y, Liu H. Water quality assessment of surface drinking water sources in cities and towns of China. Water Resour Protect. 2009;25(2):1-5. 
39. Feng HF, He QF, Xie SY, Wang JF. Evaluation and analysis of the rural drinking water quality in Chongqing karst mountainous regions-a case study on Shiqing Village of Nanping town in Nanchuan district. Earth Environ. 2010:38:54-8.

40. Kohavi R. A study of cross-validation and bootstrap for accuracy estimation and model selection. Neuroimage. 1995;14:1137-45.

41. Wang W, Gelman A. Difficulty of selecting among multilevel models using predictive accuracy. Stat Interface. 2014;7:1-15.

42. Matos JF, Dusse LMSA, Stubbert RVB, Ferreira MR, Coura-Vital W, Fernandes APSM, et al. Comparison of discriminative indices for iron deficiency anemia and $\beta$ thalassemia trait in a Brazilian population. Hematology. 2013;18(3): $169-74$.

43. Moineddin R, Matheson FI, Glazier RH. A simulation study of sample size for multilevel logistic regression models. BMC Med Res Methodol. 2007;7(1):34.

44. Chan KW, Zhang L. The hukou system and rural-urban migration in China: processes and changes. China Q. 1999;160:818-55.

45. Chan KW, Buckingham W. Is China abolishing the hukou system? China Q 2008;195:582-606.

46. Liu C, Zhou W, Feng X. Dental caries status of students from migrant primary schools in Shanghai Pudong new area. BMC Oral Health. 2016;16(1):28.

47. Su H, Yang R, Deng Q, Qian W, Yu J. Deciduous dental caries status and associated risk factors among preschool children in Xuhui District of Shanghai, China. BMC Oral Health. 2018;18(1):111.

48. Tadakamadla SK, Tadakamadla J, Kroon J, Lalloo R, Johnson NW. Effect of family characteristics on periodontal diseases in children and adolescents—a systematic review. Int J Dent Hygiene. 2020;18:3-16.

49. Fisher-Owens SA, Gansky SA, Platt L, Weintraub JA, Soobader M-J, Bramlett $M D$, et al. Influences on children's oral health: a conceptual model. Pediatrics. 2007;120(3)::510-20.

50. Kumar S, Tadakamadla J, Zimmer-Gembeck M, Kroon J, Lalloo R, Johnson NW. The effect of parenting practices on the severity of gingival bleeding in children. J Periodontol. 2017;88(8):744-51.

51. Nicolau B, Marcenes W, Hardy R, Sheiham A. A life-course approach to assess the relationship between social and psychological circumstances and gingival status in adolescents. J Clin Periodontol. 2003:30(12):1038-45.

52. Ramires-Romito ACD, Oliveira LB, Romito GA, Mayer MPA, Rodrigues CRMD. Correlation study of plaque and gingival indexes of mothers and their children. J Appl Oral Sci. 2005;13(3):227-31.

53. Shearer DM, Thomson WM, Caspi A, Moffitt TE, Broadbent JM, Poulton R Inter-generational continuity in periodontal health: findings from the Dunedin family history study. J Clin Periodontol. 2011;38(4):301-9.

54. Zhang Q, Li Z, Wang C, Shen T, Yang Y, Chotivichien S, et al. Prevalence and predictors for periodontitis among adults in China, 2010. Glob Health Action. 2014:7(1):24503.

55. Kumar S, Tadakamadla J, Johnson N. Effect of toothbrushing frequency on incidence and increment of dental caries: a systematic review and metaanalysis. J Dent Res. 2016;95(11):1230-6.

56. Yamamoto K, Okazaki A, Sakamoto Y, Funatsu M. The relationship between premenstrual symptoms, menstrual pain, irregular menstrual cycles, and psychosocial stress among Japanese college students. J Physiol Anthropol. 2009;28(3):129-36

57. Subasi F, Mumcu G, Koksal L, Cimilli H, Bitlis D. Factors affecting oral health habits among children with cerebral palsy: pilot study. Pediatr Int. 2007; 49(6):853-7.

58. Burt BA, Eklund SA. Dentistry Dental Practice and the Community. 6th ed. Philadelphia: W.B: Sounders; 2005

59. Ying-fang $T$. The problems of executing health education in rural elementary and high school and way to improve. J Phys Educ. 2002;5(9): $118-20$.

60. Behbehani JM, Shah NM. Oral health in Kuwait before the Gulf war. Med Princ Pract. 2002;11(Suppl. 1):36-43

61. Wu J, Wang WF, Zhang YD, Chen TX. Clinical features and genetic analysis of 48 patients with chronic granulomatous disease in a single center study from Shanghai, China (2005-2015): new studies and a literature review. J Immunol Res. 2017;2017:8745254.

\section{Publisher's Note}

Springer Nature remains neutral with regard to jurisdictional claims in published maps and institutional affiliations.

\section{Ready to submit your research? Choose BMC and benefit from}

- fast, convenient online submission

- thorough peer review by experienced researchers in your field

- rapid publication on acceptance

- support for research data, including large and complex data types

- gold Open Access which fosters wider collaboration and increased citations

- maximum visibility for your research: over $100 \mathrm{M}$ website views per year

At BMC, research is always in progress.

Learn more biomedcentral.com/submissions 